\title{
Reviews
}

\section{Asymmetric dimethylarginine (ADMA): a potential link between endothelial dysfunction and cardiovascular diseases in insulin resistance syndrome?}

\author{
N. N. Chan, J. C. N. Chan \\ Department of Medicine and Therapeutics, The Prince of Wales Hospital, The Chinese University of Hong Kong
}

\begin{abstract}
Endothelium-derived nitric oxide plays a major role in the regulation of vascular tone and in the maintenance of vascular homeostasis. Endothelial dysfunction with impaired nitric oxide biosynthesis and decreased bioavailability has been implicated in insulin resistance syndrome and Type II (non-insulin-dependent) diabetes mellitus. Nitric oxide is synthesised by nitric oxide synthase. Asymmetric dimethylarginine is a major endogenous nitric oxide synthase inhibitor. Increased circulating asymmetric dimethylarginine was initially found in patients with chronic renal failure and subse-
\end{abstract}

quently many other disease states. Increased asymmetric dimethylarginine plasma concentrations could contribute to the development of insulin resistance and coronary heart disease. Understanding of the pathophysiological role of asymmetric dimethylarginine could lead to novel therapies in the prevention of arteriosclerosis and coronary heart disease. [Diabetologia (2002) 45:1609-1616]

Keywords Endothelium, nitric oxide, asymmetric dimethylarginine, dimethylarginine dimethylaminohydrolase, insulin resistance syndrome.

\section{Introduction}

The insulin resistance syndrome, or metabolic syndrome X, consists of a cluster of closely linked risk factors which accelerate atherogenesis. These associ-

Received: 12 July 2002 / Revised: 16 August 2002

Published online: 30 October 2002

(C) Springer-Verlag 2002

Corresponding author: Dr. N. N. Chan, Department of Medicine and Therapeutics, The Prince of Wales Hospital, The Chinese University of Hong Kong, Shatin, New Territories, Hong Kong. E-mail: nnkachan@aol.com

Abbreviations: ADMA, asymmetric dimethylarginine; CRP, C-reactive protein; DDAH, dimethylarginine dimethylaminohydrolase; ESRD, end-stage renal disease; IMT, intima-media thickness $L$; -NMMA, $\mathrm{N}^{\mathrm{G}}$-monomethyl-L-arginine; NADPH, nicotinamide-adenine dinucleotide phosphate; NO, nitric oxide; PRMT I, protein arginine methyltransferase type I; PRMT II, protein arginine methyltransferase type II; PKC, protein kinase C; PPAR,; $\gamma$, peroxisome proliferator-activated receptor gamma; SDMA, symmetric dimethylarginine. ated risk factors include hyperinsulinaemia, hypertriglyceridaemia, increased low-density lipoprotein (LDL) cholesterol, decreased high-density lipoprotein (HDL) cholesterol, hyperuricaemia, hyperhomocysteinaemia, hypertension and Type II (non-insulin-dependent) diabetes mellitus [1]. There is growing evidence that endothelial dysfunction is also a component of the insulin resistance syndrome and Type II diabetes [2, 3]. Furthermore, defective endothelial function, manifested as impaired endothelium-dependent vasodilatation, has been shown to be independent of obesity [4] and is now widely regarded as an early event in atherogenesis. Recent clinical evidence suggests that dysfunction of the coronary endothelium strongly predicts the progression of long-term atherosclerotic disease [5], even in the absence of obstructive coronary lesions [6]. Hence endothelial dysfunction seems to be linked between insulin resistance and accelerated atherogenesis. The precise pathophysiological basis of defective endothelial function, however, remains to be elucidated. 


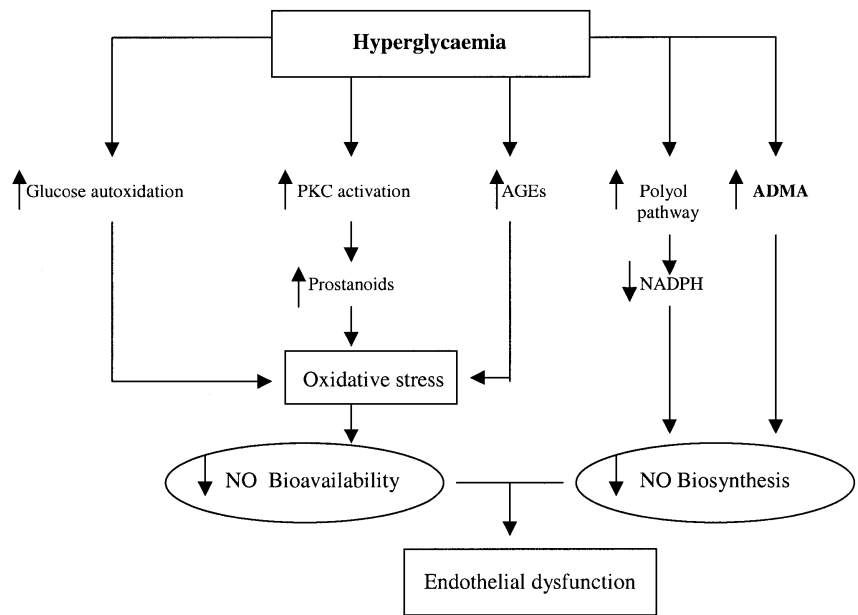

Fig. 1. Complex mechanisms through which hyperglycaemia causes endothelial dysfunction

\section{Nitric oxide pathway, insulin resistance and hyperglycaemia}

One of the most critical vasoactive mediators synthesized by the vascular endothelium is nitric oxide (NO), previously known as endothelium-derived relaxing factor [7]. Nitric oxide is synthesized from L-arginine by NO synthase. Endothelium-derived NO is a powerful endogenous vasodilator and also has important roles in the maintenance of vascular homeostasis. For instance, NO inhibits platelet aggregation, leucocyte migration and cellular adhesion to the endothelium, and attenuates vascular smooth muscle cell proliferation and migration. In addition, it inhibits activation and expression of adhesion molecules and the production of superoxide anions [8]. In Type I, Type II diabetes and insulin resistance syndrome, there is evidence that the release and/or bioavailability of NO are diminished $[9,10]$. Despite the heterogeneous nature of these conditions, they all share the same feature of increased plasma glucose concentrations which could affect the L-arginine: NO pathway. Nitric oxide bioavailability can be reduced due to increased oxidative stress which can result from increased superoxide anions production from glucose autoxidation. Hyperglycaemia-induced activation of protein kinase $\mathrm{C}$ (PKC) followed by that of phospholipase A2, results in increased production of arachidonic acid metabolites which also have potent oxidizing effects. In contrast, reduced NO synthesis can result from activation of the polyol pathway which increases the utilization of nicotinamideadenine dinucleotide phosphate (NADPH), an important cofactor in the biosynthesis of NO. Furthermore, accumulation of AGE due to non-enzymatic crosslinking of proteins, could quench $\mathrm{NO}$, further reducing its bioavailability (Fig. 1). In addition to these mechanisms, the endogenous NO synthase inhibitor, asymmetric dimethylarginine (ADMA), has recently emerged as a key factor in determining NO biosynthe- sis. Understanding of the genetic and pathophysiological aspects of this molecule could lead to therapeutic advancement in reversing endothelial dysfunction and more importantly, prevention of diabetic vasculopathy given the unique metabolic milieu of diabetic patients.

\section{Endogenous nitric oxide synthase inhibitor: ADMA}

As early as the 1970s, it was recognised that methylated arginines are excreted in human urine [11]. Since then, methylated arginines have been detected in immune cells and neurons of animals $[12,13]$ and human endothelial cells $[14,15]$. It is now clear that two types of endogenous NO synthase inhibitors exist in the human circulation, $\mathrm{N}^{\mathrm{G}}$-monomethyl-L-arginine (L-NMMA) and ADMA [16]. The concentration of ADMA is approximately tenfold higher than that of L-NMMA and is the major inhibitor of the NO biosynthesis in humans [17].

ADMA is derived from the catabolism of proteins containing methylated arginine residues and is released as the proteins are hydrolysed. These proteins are predominately found in the nucleus and are involved in RNA processing and transcriptional control [18]. The synthesis of ADMA (and L-NMMA) requires the enzyme protein arginine methyltransferase type I (PRMT I) which methylates arginine residues [19]. Protein arginine methyltransferase type II (PRMT II) forms symmetric dimethylarginine (SDMA). SDMA is a stereoisomer of ADMA and has no direct inhibitory effect on NO synthase. All three methylarginines (ADMA, SDMA and L-NMMA) enter endothelial cells through the cationic amino acid transporters known collectively as the $\mathrm{y}^{+}$transporter. The activity of this transporter was found to co-locate with caveolin-bound NO synthase which suggests that the $\mathrm{y}^{+}$transporter activity could be an important determinant of the local concentrations of methylarginines [20]. The three methylarginines compete with each other and with arginine for transport into the cell [21]. Hence high concentrations of ADMA could potentially interfere with intracellular transport of L-arginine resulting in a decrease in NO synthesis. The transport system concentrates methylarginines within the endothelial cells such that intracellular concentrations are greater than circulating concentrations. In this regard, a defective $\mathrm{y}^{+}$transporter system could result in a higher concentration of circulating ADMA leading to decreased NO biosynthesis. Hence the $\mathrm{y}^{+}$transporter system could be a potential site of defect in disease states.

\section{Degradation of ADMA: role of DDAH}

Although a proportion of ADMA is excreted in the urine and therefore accumulates in patients with renal failure [22, 23], its major catabolism is via the enzyme dimethylarginine dimethylaminohydrolase (DDAH) in 
vivo [24]. The crystal structure of DDAH has been characterised [25]. Two isoforms of DDAH have been identified in every cell type examined: DDAH I is typically found in tissues expressing neuronal NOS, whereas DDAH II predominates in tissues containing the endothelial isoform of NOS [26]. There is a constant production of ADMA in the course of protein turnover. This is supported by the observation that addition of the DDAH inhibitor $4124 \mathrm{~W}$ to a vascular segment in vitro induces vasoconstriction which is reversed by adding L-arginine to the medium [24]. ADMA undergoes extensive metabolism by DDAH to citrulline and dimethylamine, such that only $5 \%$ of parenterally administered ADMA is recovered in the urine [23]. DDAH is specific for ADMA and has no effect on SDMA. This is supported by data showing that the use of $4124 \mathrm{~W}$ causes accumulation of ADMA in vitro whereas SDMA remains unaffected [24]. Given the central role of DDAH in the regulation of ADMA degradation, any disease that decreases DDAH activity would be expected to increase circulating ADMA concentrations. Increased ADMA in turn leads to diminished NO biosynthesis and endothelial dysfunction. Apart from renal impairment which will reduce ADMA clearance, hypercholesterolaemia could directly reduce DDAH activity resulting in ADMA accumulation. When cultured endothelial cells were exposed to oxidized LDL-cholesterol, ADMA accumulated in the medium at a faster rate than when cells were treated with vehicle or native LDL-cholesterol. This effect was accompanied by a temporally related decline in DDAH activity [27]. Similar observations were also made in the context of hyperglycaemia [17]. The vitamin A derivative, all-transretinoic acid has been shown to increase the expression of DDAH II, a likely mechanism through which alltrans-retinoic acid increases NO synthesis by endothelial cells (via reduction of ADMA) [28].

\section{ADMA and endothelial dysfunction in disease states}

The role of ADMA in endothelial dysfunction has been studied in several conditions with particular attention given to renal failure. Accumulation of ADMA in humans was first shown in chronic renal failure in the early 1990's [22] and was subsequently confirmed by others [29, 30, 31, 32]. Conversely, short-term reduction of circulating ADMA (amongst other toxins in renal failure) by haemodialysis was shown to improve flow-mediated dilatation (FMD) [31]. In addition, ADMA is a potential mediator of impaired FMD in experimental hyperhomocysteinaemia in humans [33]. It has been shown that by increasing plasma homocysteine concentrations using methionine infusion, FMD is impaired and this is associated with increased plasma ADMA [33]. Increased plasma concentrations of ADMA have also been described in a number of other conditions
Table 1. Conditions in which increased ADMA concentrations have been found in animals

\begin{tabular}{|c|c|}
\hline Conditions & Authors \\
\hline Hypertension & $\begin{array}{l}\text { Matsuoka, et al. } 1997[34] \\
\text { Goonasekera, et al. } 2000[74]\end{array}$ \\
\hline Alloxan-induced hyperglycaemia & Masuda, et al. 1999 [41] \\
\hline Hyperhomocysteinaemia & $\begin{array}{l}\text { Boger, et al. } 2000 \text { [47] } \\
\text { Stuhlinger, et al. } 2001 \text { [42] }\end{array}$ \\
\hline Atherosclerosis & $\begin{array}{l}\text { Boger, et al. } 1997 \text { [49] } \\
\text { Boger, et al. } 2000 \text { [47] }\end{array}$ \\
\hline Hypercholesterolaemia & $\begin{array}{l}\text { Boger, et al. } 1996[50] \\
\text { Boger, et al. } 2000 \text { [47] }\end{array}$ \\
\hline Ageing & Xiong, et al. 2001 [73] \\
\hline
\end{tabular}

Table 2. Conditions in which increased ADMA concentrations have been found in humans

\begin{tabular}{|c|c|}
\hline Conditions & Authors [References] \\
\hline \multirow{4}{*}{ Chronic renal failure } & Vallance et al. 1992 [22] \\
\hline & Marescau et al. 1997 [30] \\
\hline & Zoccali et al. 2001 [32] \\
\hline & Kielstein et al. 2002 [29] \\
\hline Essential hypertension & Surdacki et al. 1999 [53] \\
\hline \multirow[t]{2}{*}{ Childhood hypertension } & Goonasekera et al. 1997 [36] \\
\hline & Goonasekera et al. 2000 [74] \\
\hline Hypercholesterolaemia & Boger et al. 1998 [38] \\
\hline Hypertriglyceridaemia & Lundman et al. 2001 [46] \\
\hline Post-prandial dyslipidaemia & Fard et al. 2000 [40] \\
\hline Hyperhomocysteinaemia & Boger et al. 2001 [43] \\
\hline Atherosclerosis & Miyazaki et al. 1999 [35] \\
\hline Pre-eclampsia & Pattersson et al. 1998 [39] \\
\hline \multirow[t]{2}{*}{ Type II diabetes mellitus } & Ito et al. 1999 [44] \\
\hline & Abbasi et al. 2001 [52] \\
\hline Stroke & Yoo and Lee 2001 [37] \\
\hline Peripheral vascular disease & Boger et al. 1997 [51] \\
\hline Congestive heart failure & Usui et al. 1998 [45] \\
\hline Congenital heart disease & Gorenflo et al. 2001 [75] \\
\hline Pulmonary hypertension & Gorenflo et al. 2001 [75] \\
\hline Thrombotic microangiopathy & Herlitz et al. 1997 [48] \\
\hline Schizophrenia & Das et al. 1996 [55] \\
\hline
\end{tabular}

(Tables 1,2) including diabetes mellitus, hypercholesterolaemia, hypertriglyceridaemia, hypertension, preeclampsia, stroke, peripheral vascular disease, congestive heart failure and acute coronary events $[34,35$, $36,37,38,39,40,41,42,43,44,45,46,47,48,49$, $50,51,52,53,54]$. Of interest, increased ADMA concentrations have also been implicated in the pathogenesis of conditions not affecting the cardiovascular system such as schizophrenia although the exact mechanism has yet to be clarified [55].

\section{ADMA, insulin resistance and cardiovascular disease}

Increased ADMA concentrations in plasma are associated with conditions closely related to the insulin re- 
sistance syndrome (Table 2). These conditions include hypertriglyceridaemia, hyperglycaemia, hyperhomocysteinaemia and essential hypertension. Furthermore, uremia is strongly linked to insulin resistance. This has been attributed to post-receptor defects in insulin action in muscle, adipose tissue and liver [56]. Given the metabolic abnormalities of diabetic patients and their high risk for renal dysfunction, ADMA could represent an important linking factor for the impaired endothelium-dependent vasodilatation and increased cardiovascular risks in Type II diabetes, especially in the presence of impaired renal function. A crosssectional study has shown that plasma concentrations of ADMA were positively correlated with insulin resistance independent of other risk factors [57]. In this study, insulin sensitivity was determined by insulin-mediated glucose disposal in non-diabetic, normotensive people. High ADMA concentrations were associated with high fasting triglyceride but not LDL-cholesterol concentrations. It has been shown that treatment with an insulin-sensitizing drug, rosiglitazone, enhanced insulin sensitivity and reduced plasma ADMA concentrations [57]. Although this study proves the direct therapeutic role of rosiglitazone in reducing plasma ADMA concentration, there is a clear association between insulin resistance and high circulating ADMA concentrations. It is now established that activation by thiazolidinediones of the peroxisome proliferator-activated receptor gamma $(\operatorname{PPAR} \gamma)$ induces differentiation of preadipocytes into mature fat cells leading to increased non-esterified fatty acid (NEFA) uptake and decreases their plasma concentrations in circulating NEFA. This is often accompanied by a reduction in plasma glucose concentrations and oxidative stress. The ADMA lowering effect of thiazolidinedione [57] could be mediated through a reduction in oxidative stress, increased DDAH activity and/or hence increased ADMA degradation (Fig. 2).

Similarly, metformin has been shown to decrease circulating ADMA both as monotherapy and as addon therapy to sulphonylurea in poorly controlled Type II diabetic patients [58]. Of note, treatment with both rosiglitazone and metformin results in favourable changes in other metabolic risk factors in addition to improving insulin resistance. The observed reduction in circulating ADMA could relate to the metabolic changes induced and be a direct consequence of improved insulin sensitivity.

The adverse effects of ADMA accumulation on endothelial cell function is well established and is associated with worsening of clinical endpoints. In the MONICA (monitoring of trends and determinants in cardiovascular disease) cohort, high concentrations of ADMA were associated with an increased risk of acute coronary events among non-smoking middleaged men, especially those with previous coronary heart disease [54]. This finding provided evidence for

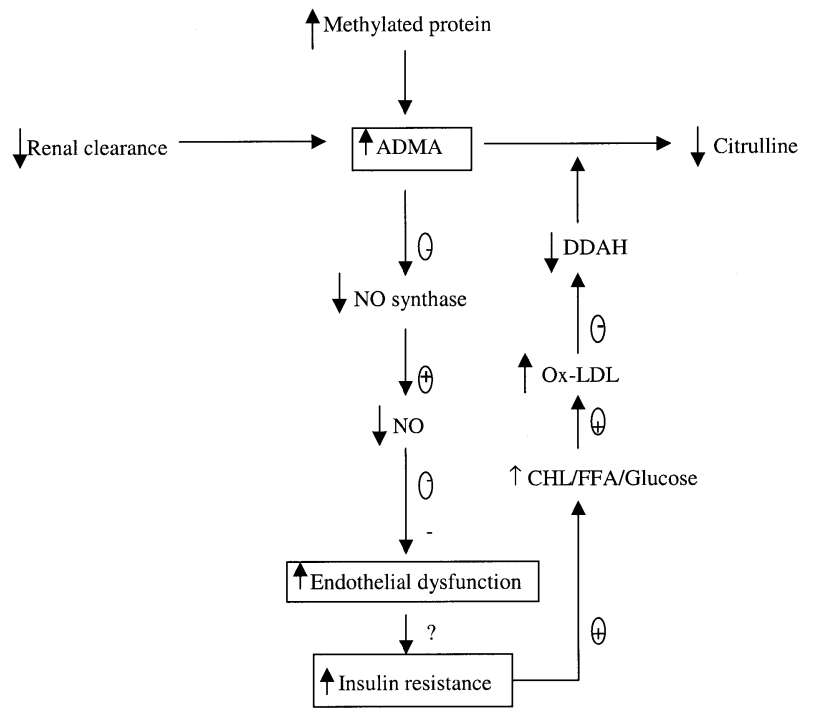

Fig. 2. The complex relations showing the metabolism of ADMA and its putative role in the pathogenesis of insulin resistance. Increased in serum NEFA, glucose and lipid concentrations in insulin resistance syndrome could increase oxidative stress leading to increased oxidized LDL formation which could suppress the activity of DDHA resulting in diminished ADMA degradation. The latter perpetuates the vicious cycle by reducing NO synthase leading to endothelial dysfunction which worsens insulin resistance

the possible aetiological role of ADMA through NOmediated endothelial dysfunction in the development of coronary heart disease (Fig. 2). Albeit controversies continue with regard to the relation between insulin resistance and endothelial dysfunction, some reports show that insulin resistant subjects, notably those with Type II diabetes and obesity [59, 60], have impaired skeletal blood flow and reduced peripheral glucose uptake even despite high therapeutic insulin treatment. Since the acute vasodilating effects of insulin is primarily NO-mediated, such attenuated vascular response to insulin might be due to ADMA-mediated endothelial dysfunction.

\section{ADMA, inflammation and renal diseases}

It is widely accepted that inflammation plays an integral part in atherogenesis [61] and that the increase of inflammatory markers such as C-reactive proteins (CRP) predict future coronary events [62, 63]. At present, there is no proof of any association of ADMA and CRP levels in acute inflammation but since CRP is closely linked to insulin resistance [63], it is tempting to presume such association. This contention is supported by a recent prospective study in patients with end-stage renal disease (ESRD) on haemodialysis in whom changes in carotid intima-media thickness (IMT) were independently related to plasma ADMA concentrations and serum CRP [64]. In parallel, ADMA and CRP were strongly interrelated which 
emerged as the sole independent predictor of intimal lesion progression [64]. These findings clearly need to be confirmed in other patient populations as patients with ESRD are not only a heterogeneous group but their underlying renal pathology could well contribute to high plasma CRP concentrations. Nevertheless, these complex inter-relations could exist between ADMA, inflammatory markers, endothelial function, insulin resistance, renal dysfunction and cardiovascular disease.

\section{Therapeutic modulation of ADMA concentrations}

Given the pivotal role of ADMA in determining NO bioavailability and the large array of conditions associated with high ADMA concentrations, pharmacological modulation of circulating ADMA could lead to novel therapies for preventing cardiovascular disease in insulin resistant or high risk subjects. Although there is as yet only limited research in this field, a pilot study carried out with incremental doses of rosiglitazone given to seven hyperactive insulin-resistant subjects resulted in a reduction in plasma ADMA concentrations over a 12-week treatment period and improved insulin sensitivity, whereas arterial blood pressure remained unchanged [57]. Although a definitive conclusion cannot be drawn from this study, it supports the hypothesis of a link between ADMA and insulin sensitivity. Similarly, metformin seems to have ADMA-lowering effect in Type II diabetic patients [58], but again it is not clear whether a reduction in ADMA concentration was due to direct metformin action or occurred in parallel with the improvement of other metabolic indices.

Reduction of plasma ADMA concentration has also been seen in response to probucol in rats [65]. In contrast, administration of L-arginine, the key substrate for NO synthase in the biosynthesis of NO, does not alter ADMA concentration but increased the L-arginine to ADMA ratio resulting in improved endothelium-dependent vasodilatation in animals and humans $[38,49,50]$. Of note, patients with unstable angina and reduced endothelium-dependent coronary vasodilatation had markedly improved anginal symptoms after 6 months of therapy with L-arginine (9 g/day) [66]. The same 3 days of oral supplementation with $6 \mathrm{~g}$ of L-arginine daily increase treadmill exercise capacity by $30 \%$ in patients with stable angina [67]. More recently, the increased risk for CHD in patients with impaired fasting glycaemia in the Cholesterol and Recurrent Events (CARE) trial was substantially reduced by statins [68]. Since statins have various pleiotrophic effects independent of their lipid-lowering effects, it was suggested that statins can also reduce plasma ADMA concentration and hence improve endothelial function [69]. This hypothesis is plausible because statins reduce CRP concentrations $[62,63,70]$ and
$\mathrm{CRP}$ has been shown to be closely related to ADMA concentrations [64]. In this regard, retrospective measurement of ADMA concentrations in various lipidlowering trials could provide useful information. In the HOPE study, renal insufficiency, a condition in which plasma ADMA is known to be increased, is a predictor of cardiovascular outcomes and ramipril reduces cardiovascular events in both diabetic and nondiabetic subjects with mild renal insufficiency independent of its blood pressure-lowering effect [71]. In a recent small randomised study of hypertensive patients, perindopril and losartan monotherapy, but not bisoprolol have been shown to reduce circulating ADMA [72]. Taken together, these pilot studies suggest that future development of drugs with specific ADMA-lowering effects could prove more effective than conventional drugs in the treatment of specific conditions in which increased ADMA plays a crucial pathophysiological role.

\section{Conclusions and future directions}

ADMA is the major endogenous NOS inhibitor, and its accumulation has been associated with atherosclerosis and cardiovascular disease. The association between high ADMA concentrations with various components of the insulin resistance syndrome is particularly intriguing and it is plausible that ADMA may serve as a pivotal link between insulin resistance, intermediary metabolism (lipid and glucose), endothelial dysfunction and cardiovascular diseases. Several potential therapeutic drugs have shown early promise in reducing plasma ADMA concentrations. Whether lowering plasma ADMA concentrations could translate into a reduction in acute cardiovascular events remains to be proven in prospective studies. Additional work would be required to determine the precise mechanisms whereby specific conditions lead to its accumulation. Furthermore, animal studies utilizing DDAH knockout approach or identification of genetic variants of DDAH would provide additional insight into the genetic predisposition of individuals to premature cardiovascular diseases.

Sources. This review is based on the relevant literature published in the English language during the period 1966 to 2002. The sources available to the authors were integrated with sources identified through PubMed searches for "ADMA", "insulin resistance syndrome", and "endothelial dysfunction".

\section{References}

1. Reaven GM (1998) Banting Lecture 1988: role of insulin resistance in human disease. Diabetes 37:15951607 
2. McVeigh GE, Brennan GM, Johnston GD et al. (1992) Impaired endothelium-dependent and independent vasodilatation in patients with type 2 [non-insulin-dependent] diabetes mellitus. Diabetologia 35:771-776

3. Williams SB, Cusco JA, Roddy M-A, Johnstone MT, Creager MA (1996) Impaired nitric oxide-mediated vasodilatation in patients with non-insulin-dependent diabetes mellitus. J Am Coll Cardiol 27:567-574

4. Hogikyan RV, Galecki AT, Pitt B, Halter JB, Greene DA, Supiano MA (1998) Specific impairment of endotheliumdependent vasodilatation in subjects with Type 2 diabetes independent of obesity. J Clin Endocrinol Metab 83:19461952

5. Schachinger V, Britten MB, Zeiher AM (2000) Prognostic impact of coronary vasodilator dysfunction on adverse long-term outcome of coronary heart disease. Circulation 101:1899-1906

6. Suwaidi JA, Hamasaki S, Higano ST, Nishimura RA, Holmes DR Jr, Lerman A (2000) Long-term follow-up of patients with mild coronary artery disease and endothelial dysfunction. Circulation 101:948-954

7. Palmer RMJ, Ferrige AG, Moncada S (1987) Nitric oxide release accounts for the biological activity of endotheliumderived relaxing factor. Nature 327:524-526

8. Vallance P, Chan NN (2001) Endothelial function and nitric oxide: clinical relevance. Heart 85:342-350

9. De Vriese AS, Verbeuren TJ, Van de Voorde J, Lameire NH, Vanhoutte PM (2000) Endothelial dysfunction in diabetes. Br J Pharmacol 130:963-974

10. Chan NN, Vallance P, Colhoun HM (2000) Nitric oxide and vascular responses in Type I diabetes. Diabetologia 43:137-147

11. Kakimoto Y, Akazawa S (1970) Isolation and identification of $\mathrm{NG}^{\mathrm{G}}, \mathrm{NG}_{-}$, and $\mathrm{NG}^{\mathrm{G}}, \mathrm{N}^{\prime} \mathrm{G}_{-}$-dimethyl-arginine, N-mono, di, and trimethyllysine, and glucosylgalactosyl-, and galactosyl- $\delta$-hydroxylysine from human urine. J Biol Chem 245:5751-5758

12. Kimoto M, Tsuji H, Ogawa T, Sasaoka K (1993) Detection of $\mathrm{N}^{G} \mathrm{~N}^{\mathrm{G}}$ dimethylarginine dimethylaminohydrolase in the nitric oxide generating systems of rats using monoclonal antibody. Arch Biochem Biophys 300:657-662

13. Ueno S, Sano A, Kotani K, Kondoh K, Kakimoto Y (1992) Distribution of free methylarginines in rat tissues and in the bovine brain. J Neurochem 59:2012-2016

14. Forstermann U, Closs EI, Pollock JS et al. (1994) Nitric oxide synthase isozymes. Characterization, purification, molecular cloning, and functions. Hypertension 23:1121-1131

15. MacAllister RJ, Fickling SA, Whitley GS (1994) Metabolism of methylarginines by human vasculature; implications for the regulation of nitric oxide synthesis. Br J Pharmacol 112:43-48

16. Vallance P, Leone A, Calver A, Collier J, Moncada S (1992) Endogenous dimethylarginine as an inhibitor of nitric oxide synthesis. J Cardiovasc Pharmacol 20 [Suppl 12]:S60-S62

17. Cooke JP (2000) Does ADMA cause endothelial dysfunction? Arterioscler Thromb Vasc Biol 20:2032-2037

18. Najbauer J, Johnson BA, Young AL et al. (1993) Peptides with sequences similar to glycine, arginine-rich motifs in proteins interacting with RNA are efficiently recognised by methyltransferase[s] modifying arginine in numerous proteins. J Biol Chem 268:10501-10509

19. Ghosh SK, Paik WK, Kim S (1988) Purification and molecular identification of two protein methylases I from calf brain: myelin basic protein- and histone-specific enzyme. J Biol Chem 263:19024-19033
20. McDonald KK, Zharikov S, Block ER, Kilberg MS (1997) A caveolar complex between the cationic amino acid transport I and endothelial nitric oxide synthase may explain the 'arginine paradox' J Biol Chem 272:31213-31216

21. Leiper J, Vallance P (1999) Biological significance of endogenous methylarginines that inhibit nitric oxide synthases. Cardiovasc Res 43:542-548

22. Vallance P, Leone A, Calver A, Collier J, Moncada S (1992) Accumulation of an endogenous inhibitor of nitric oxide synthesis in chronic renal failure. Lancet 339:572575

23. McDermott JR (1976) Studies on the catebolism of $\mathrm{NG}^{\mathrm{G}} \mathrm{N}^{\prime} \mathrm{G}$-dimethylarginine and $\mathrm{NG}^{\mathrm{G}}, \mathrm{NG}^{\mathrm{G}}$-dimethylargininein the rabbit. Biochem J 154:179-184

24. MacAllister RJ, Parry H, Kimoto M et al. (1996) Regulation of nitric oxide synthesis by dimethylarginine dimethylaminohydrolases. Br J Pharmacol 119:1533-1540

25. Murray-Rust J, Leiper J, McAlister M et al. (2001) Structural insights into the hydrolysis of cellular nitric oxide synthase inhibitors by dimethylarginine dimethylaminohydrolase. Nat Struct Biol 8:679-683

26. Leiper JM, Santa MJ, Chubb A et al. (1999) Identification of two human dimethylarginine dimethylaminohydrolases with distinct tissue distributions and homology with microbial arginine deiminases. Biochem J 343:209-214

27. Ito A, Tsao PS, Adimoolam, Kimoto M, Ogawa T, Cooke JP (1999) Novel mechanism for endothelial dysfunction: dysregulation of dimethylarginine dimethylaminohydrolase. Circulation 99:3092-3095

28. Achan V, Tran CTL, Arrigoni F, Whitley GS, Leiper JM, Vallance P (2002) all-trans-Retinoic acid increases nitric oxide synthsis by endothelial cells. A role for the induction of dimethylarginine dimethylaminohydrolase. Circ Res 90:764-769

29. Kielstein JT, Boger RH, Bode-Boger SM et al. (2002) Marked increase of asymmetric dimethylarginine in patients with incipient primary chronic renal disease. J Am Soc Nephrol 13:170-176

30. Marescau B, Nagels G, Possemiers I et al. (1997) Guanidino compounds in serum and urine of non-dialyzed patients with chronic renal insufficiency. Metabolism 46:1024-1031

31. Cross JM, Donald A, Vallance PJ, Deanfield JE, Woolfson RG, MacAllister RJ (2001) Dialysis improves endothelial function in humans. Nephrol Dial Transplant 16:18231829

32. Zoccali C, Bode-Boger SM, Mallamaci F et al. (2001) Plasma concentration of asymmetrical dimethylarginine and mortality in patients with end-stage renal disease: a prospective study. Lancet 358:2113-2117

33. Boger RH, Lentz SR, Boge-Boger SM, Knapp HR, Haynes WG (2001) Elevation of asymmetrical dimethylarginine may mediate endothelial dysfunction during experimental hyperhomocysteinaemia in humans. Clin Sci (Colch) 100:161-167

34. Matsuoka H, Itoh S, Kimoto M et al. (1997) Asymmetrical dimethylarginine, an endogenous nitric oxide synthase inhibitor, in experimental hypertension. Hypertension 29:242-247

35. Miyazaki H, Matsuoka H, Cooke JP et al. (1999) Endogenous nitric oxide synthase inhibitor - a novel marker of atherosclerosis. Circulation 99:1141-1146

36. Goonasekera CDA, Rees DD, Woolard P et al. (1997) Nitric oxide synthase inhibitors and hypertension in children and adolescents. J Hypertens 15:901-909

37. Yoo J-H, Lee S-C (2001) Elevated levels of plasma homocysteine and asymmetric dimethylarginine in elderly patients with stroke. Atherosclerosis 158:425-430 
38. Boger RH, Bode-Boger SM, Szuba A et al. (1998) Asymmetric dimethylarginine [ADMA]: a novel risk factor for endothelial dysfunction. Its role in hypercholesterolemia. Circulation 98:1842-1847

39. Pattersson A, Hedner T, Milsom I (1998) Increased concentrations of asymmetric dimethylarginine [ADMA], an endogenous inhibitor of nitric oxide synthase, in preeclampsia. Acta Obstet Gynecol Scand 77:808-813

40. Fard A, Tuck CH, Donis JA et al. (2000) Acute elevation of plasma asymmetric dimethylarginine and impaired endothelial function in response to a high-fat meal in patients with type 2 diabetes. Arterioscler Thromb Vasc Biol 20:2039-2044

41. Masuda H, Goto M, Tamaoli S, Azuma H (1999) Accelerated intimal hyperplasia and increased endogenous inhibitors for NO synthesis in rabbits with alloxan-induced hyperglycaemia. Br J Pharmacol 126:211-218

42. Stuhlinger MC, Tsao PS, Her J-H, Kimoto M, Balint RF, Cooke JP (2001) Homocysteine impairs the nitric oxide synthase pathway. Role of asymmetric dimethylarginine. Circulation 104:2569-2575

43. Boger RH, Lentz SR, Bode-Boger SM, Knapp HR, Haynes WG (2001) Elevation of asymmetrical dimethylarginine may mediate endothelial dysfunction during experimental hyperhomocysteinaemia in humans. Clin Sci (Colch) 100:161-167

44. Ito A, Asagami T, Tsao PS et al. (1999) Dysregulation of dimethylarginine dimethylaminohydrolase: a mechanism of endothelial dysfunction in diabetes mellitus. Circulation 100 [suppl I]:I-473

45. Usui M, Matsuoka H, Miyazaki H, Ueda S, Okuda S, Imaizumi T (1998) Increased endogenous nitric oxide synthase inhibitor in patients with congestive heart failure. Life Sci 62:2425-2430

46. Lundman PP, Eriksson MJ, Stuhlinger M, Cooke JP, Hamsten A, Tornvall P (2001) Mild-to-moderate hypertriglyceridaemia in young men is associated with endothelial dysfunction and increased plasma concentrations of asymmetrical dimethylarginine. J Am Coll Cardiol 38:111-116

47. Boger RH, Bode-Boger SM, Sydow K, Heistad DD, Lentz SR (2000) Plasma concentration of asymmetrical dimethylarginine, an endogenous inhibitor of nitric oxide synthase, is elevated in monkeys with hyperhomocysteinemia or hypercholesterolemia. Arterioscler Thromb Vasc Biol 20:1557-1564

48. Herlitz H, Petersson A, Sigstrom L, Wennmalm A, Westberg G (1997) The arginine-nitric oxide pathway in thrombotic microangiopathy. Scand J Urol Nephrol 31:477-479

49. Boger RH, Bode-Boger SM, Brandes RP et al. (1997) Dietary L-arginine reduces the progression of atherosclerosis in cholesterol fed rabbits: comparison with lovastatin. Circulation 96:1282-1290

50. Boger RH, Bode-Boger SM, Kienke S et al. (1996) Elevated L-arginine/dimethylarginine ratio contributes to enhanced systemic NO production by dietary L-arginine in hypercholesterolemic rabbits. Biochem Biophys Res Commun 219:598-603

51. Boger RH, Bode-Boger SM, Thiele W, Junker W, Alexander K, Frolich JC (1997) Biochemical evidence for impaired nitric oxide synthesis in patients with peripheral arterial occlusive disease. Circulation 95:2068-2074

52. Abbasi F, Asagami T, Cooke JP et al. (2001) Plasma concentrations of asymmetric dimethylarginine are increased in patients with type 2 diabetes mellitus. Am J Cardiol 88:1201-1203
53. Surdacki A, Nowicki M, Sandmann J et al. (1999) Reduced urinary excretion of nitric oxide metabolites and increased plasma levels of asymmetric dimethylarginine in men with essential hypertension. J Cardiovasc Pharmacol 33:652658

54. Valkonen V-P, Palva H, Salonen JT et al. (2001) Risk of acute coronary events and serum concentration of asymmetrical dimethylarginine. Lancet 358:2127-2128

55. Das I, Khan NS, Puri BK, Hirsch SR (1996) Elevated endogenous nitric oxide synthase inhibitor in schizophrenic plasma may reflect abnormalities in brain nitric oxide production. Neurosci Lett 215:209-211

56. Hager SR (1989) Insulin resistance of uremia. Am J Kidney Dis 14:272-276

57. Stuhlinger MC, Abbasi F, Chu JW et al. (2002) Relationship between insulin resistance and an endogenous nitric oxide synthase inhibitor. JAMA 2877:1420-1426

58. Asagami T, Abbasi F, Stuelinger M et al. (2002) Metformin treatment lowers asymmetric dimethylarginine concentrations in patients with type 2 diabetes. Metabolism 51:843-846

59. Steinberg HO, Baron AD (2002) Vascular function, insulin resistance and fatty acids. Diabetologia 45:623-634

60. Laakso M, Edelman SV, Brechtel G, Baron AD (1990) Decreased effect of insulin to stimulate skeletal muscle blood flow in obese men. J Clin Invest 85:1844-1852

61. Ross R (1999) Atherosclerosis: an inflammatory disease. N Engl J Med 340:115-126

62. Ridker PM, Rifai N, Clearfield M et al. (2001) Measurement of C-reactive protein for the targeting of statin therapy in the primary prevention of acute coronary events. $\mathrm{N}$ Engl J Med 344:1959-1965

63. Albert MA, Danielson E, Rifai N, Ridker PM (2001) Effect of statin therapy on C-reactive protein levels: the pravastatin inflammation/CRP evaluation [PRINCE]: a randomized trial and cohort study. JAMA 286:64-70

64. Zoccali C, Benedetto FA, Mass R et al. (2002) CREED Investigators. Asymmetric dimethylarginine, C-reactive protein, and carotid intima-media thickness in end-stage renal disease. J Am Soc Nephrol 13:490-496

65. Jiang JL, Li NS, Deng HW (2002) Probucol preserves endothelial function by reduction of the endogenous nitric oxide synthase inhibitor level. Br J Pharmacol 135:11751182

66. Lerman A, Burnett JC, Higano ST, McKinley LJ, Holmes DR Jr (1998) Long-term L-arginine supplementation improves small-vessel coronary endothelial function in humans. Circulation 97:2123-2128

67. Ceremuzynski L, Chamiec T, Herbaczynska-Cedro (1997) Effect of supplemental oral L-arginine on exercise capacity in patients with stable angina pectoris. Am J Cardiol 80:331-333

68. Goldberg RB, Mellies MJ, Sacks FM et al. for the CARE Investigators (1998) Cardiovascular events and their reduction with pravastatin in diabetic and glucose-intolerant myocardial infarction survivors with average cholesterol levels. Circulation 98:2513-2519

69. Nash DT (2002) Insulin resistance, ADMA levels, and cardiovascular disease. JAMA 287:1451-1452

70. Tan KCB, Chow WS, Tam SC, Ai VH, Lam CH, Lam KS (2002) Atorvastatin lowers C-reactive protein and improves endothelium-dependent vasodilation in type 2 diabetes mellitus. J Clin Endocrinol Metab 87:563-568

71. Mann JF, Gerstein HC, Pogue J, Bosch J, Yusuf S (2001) Renal insufficiency as a predictor of cardiovascular outcomes and the impact of ramipril: the HOPE randomized trial. Ann Intern Med 134:629-636 
72. Ito A, Egashira K, Narishige T, Muramatsu K, Takeshita A (2001) Renin-angiotensin system is involved in the mechanism of increased serum asymmetric dimethylarginine in essential hypertension. Jpn Circ J 65:775778

73. Xiong Y, Yuan L-W, Deng H-W, Li Y-J, Chen B-M (2001) Elevated serum endogenous inhibitors of nitric oxide synthase and endothelial dysfunction in aged rats. Clin Exp Pharmacol Physiol 28:842-847
74. Goonasekera CD, Shah V, Rees DD, Dillon MJ (2000) Vascular endothelial cell activation associated with increased plasma asymmetric dimethyl arginine in children and young adults with hypertension: a basis for atheroma? Blood Press 9:16-21

75. Gorenflo M, Zheng C, Werle E, Fiehn W, Ulmer HE (2001) Plasma levels of asymmetrical dimethyl-L-arginine in patients with congenital heart disease and pulmonary hypertension. J Cardiovasc Pharmacol 37:489-492 